\title{
Aberrations of $6 q 13$ mapped to the COL12A1 locus in chondromyxoid fibroma
}

\author{
Taketoshi Yasuda $^{1,7}$, Jun Nishio ${ }^{1,7}$, Janos Sumegi ${ }^{2}$, Kayla M Kapels ${ }^{1}$, Pamela A Althof ${ }^{1}$, \\ Jeffrey R Sawyer ${ }^{3}$, John D Reith ${ }^{4}$ and Julia A Bridge ${ }^{1,5,6}$ \\ ${ }^{1}$ Department of Pathology and Microbiology, University of Nebraska Medical Center, Omaha, NE, USA; \\ ${ }^{2}$ Department of Pediatrics, Cincinnati Children's Hospital, Cincinnati, OH, USA; ${ }^{3}$ Department of Pathology, \\ University of Arkansas for Medical Sciences, Little Rock, AR, USA; ${ }^{4}$ Department of Pathology, Immunology, \\ and Laboratory Medicine, Unit of Bone and Soft Tissue Pathology, University of Florida Health Sciences, \\ Gainesville, FL, USA; ${ }^{5}$ Department of Pediatrics, University of Nebraska Medical Center, Omaha, NE, USA \\ and ${ }^{6}$ Department of Orthopaedic Surgery, University of Nebraska Medical Center, Omaha, NE, USA
}

\begin{abstract}
Chondromyxoid fibroma, a rare benign bone tumor, may be mistaken for chondrosarcoma. Although cytogenetic studies of chondromyxoid fibroma are few, rearrangements of the long arm of chromosome 6 , frequently expressed as an inv(6)(p25q13), are prominent. In this study, conventional cytogenetic analysis of 16 chondromyxoid fibroma samples from 14 patients revealed rearrangements of chromosome 6 in 10 of 11 clonally abnormal specimens. In addition to $6 q 13$ rearrangements, recurrent 6 p25 and $6 q 25$ anomalies were detected. Notably, an identical $t(6 ; 9)(q 25 ; q 22)$ translocation was identified in two cases, suggesting that it represents a distinct translocation of chondromyxoid fibroma. In an effort to further define the aberrant $6 q 13$ breakpoint and identify the molecular consequences, a fluorescence in situ hybridization (FISH)-based positional cloning strategy on chondromyxoid fibroma abnormal metaphase and interphase cells using a series of bacterial and plasmid artificial chromosome (BAC/PAC) probe combinations spanning a $6.1 \mathrm{Mb}$ region was employed. The breakpoint on $6 q 13$ was located within the COL12A1 gene, a collagen gene purportedly involved in another benign bone tumor, subungual exostosis. The findings of this study expand our knowledge of chromosomal alterations in chondromyxoid fibroma, identify COL12A1 as the likely gene candidate within the recurrent 6 q13 breakpoint, and provide an alternative approach for detecting 6 q13 anomalies in nondividing cells of chondromyxoid fibroma. The latter could potentially be utilized as an adjunct in diagnostically challenging cases.

Modern Pathology (2009) 22, 1499-1506 doi:10.1038/modpathol.2009.101; published online 31 July 2009
\end{abstract}

Keywords: chondromyxoid fibroma; cytogenetics; fluorescence in situ hybridization; COL12A1

Chondromyxoid fibroma is a rare benign tumor of bone that was first described by Jaffe and Lichten$\operatorname{stein}^{1}$ in 1948. Chondromyxoid fibroma most commonly arises in the second and third decades of life $^{2,3}$ and typically involves the metaphysis of long bones. Histopathologically, the tumor is characterized by spindle shaped or stellate cells with round to oval nuclei and eosinophillic cytoplasm

Correspondence: Dr JA Bridge, MD, Department of Pathology and Microbiology, University of Nebraska Medical Center, 983135 Nebraska Medical Center, Omaha, NE 68198-3135, USA.

E-mail: jbridge@unmc.edu

${ }^{7}$ These authors contributed equally to this work.

Received 23 April 2009; revised 13 June 2009; accepted 16 June 2009; published online 31 July 2009 embedded in a myxoid or chondroid matrix. ${ }^{4}$ Multinucleated osteoclast-like giant cells are often present at the periphery of the lobules. Approximately $18 \%$ of tumors show enlarged, hyperchromatic, and pleomorphic nuclei that may suggest malignancy, in particular chondrosarcoma. ${ }^{3}$

Few cases of chondromyxoid fibroma have been cytogenetically characterized. ${ }^{5-15}$ Clonal abnormalities of chromosome 6 are prominent and have involved the following three recurrent breakpoints: 6p25, 6q13, and 6q25. A chromosome 6 pericentric inversion involving bands p25 and q13 has been described as the sole anomaly in two chondromyxoid fibromas ${ }^{9,12}$ and as a component of more complex karyotypes in three other chondromyxoid fibromas. ${ }^{8,9,11}$ In this study, an identical 
inv(6)(p25q13) was detected in additional chondromyxoid fibroma cases, as also a novel recurrent translocation $\mathrm{t}(6 ; 9)(\mathrm{q} 25 ; \mathrm{q} 22) .{ }^{10}$ Moreover, a detailed molecular cytogenetic investigation of the 6q13 breakpoint strongly suggesting the collagen gene COL12A1 is the target gene involved is reported.

\section{Materials and methods}

\section{Tumor Samples}

A total of 16 chondromyxoid fibromas arising in 14 patients, 6 males and 8 females, were included in this study. The clinicohistopathologic features of the patients and corresponding tumors are listed in Table 1. The karyotypes for three of these patients have been reported previously (cases 8-10)., ${ }^{8,10}$ All cases were histologically characterized according to established criteria (Figure 1). ${ }^{2}$

\section{Cytogenetic Analysis}

Cytogenetic analysis was performed on sterile, representative tissue of each case using standard culture and harvest procedures, as described previously. ${ }^{16}$ Briefly, the tissues were disaggregated mechanically and enzymatically, and then cultured in RPMI 1640 medium supplemented with $20 \%$ fetal bovine serum for 3-7 days. Cells were exposed overnight to colcemid $(0.02 \mu \mathrm{g} / \mathrm{ml})$. After subsequent hypotonic treatment $(0.7 \%$ sodium citrate for $20 \mathrm{~min}$ ), the preparations were fixed three times with methanol and glacial acetic acid (3:1). Metaphase cells were banded with Giemsa trypsin or Wright stain, and the karyotypes were expressed according to the International System for Human Cytogenetic Nomenclature. ${ }^{17}$

\section{Probe Design}

Molecular cytogenetic studies were conducted to further define the recurrent 6q13 breakpoint. This chromosomal band encompassing a $6.1 \mathrm{Mb}$ region was subdivided into 21 segments that sequentially spanned the entire region (Figure 2). Bacterial artificial chromosome (BAC) and P1-derived artificial chromosome (PAC) clones mapping to the chromosome band 6q13 region were identified from

Table 1 Clinicopathologic, cytogenetic, and molecular cytogenetic data

\begin{tabular}{|c|c|c|c|c|}
\hline Case & Age/sex & Location $^{\text {a }}$ (size in $\mathrm{cm}$ ) & Karyotype & $\begin{array}{l}\text { FISH } \\
\text { results }\end{array}$ \\
\hline 1 & $29 / \mathrm{M}$ & $\begin{array}{l}\text { Proximal tibia } \\
(1.7 \times 4.4 \times 5.3)\end{array}$ & 46,XY,inv(6)(p25q13)[3]/45,X,-Y,inv(6)(p25q13),-13,+mar[2]/46,XY[14] & $\mathrm{ABN}$ \\
\hline 2 & $32 / \mathrm{F}$ & $\begin{array}{l}\text { Second metatarsus } \\
(0.5 \times 1.0 \times 1.5)\end{array}$ & $46, \mathrm{XX}[18]$ & $\mathrm{N}$ \\
\hline 3a & $61 / \mathrm{F}$ & Ilium $(3.3 \times 4.0 \times 4.5)$ & $\begin{array}{l}\text { 48,XX,+der(6)del(6)(p11.2)del(6)(q12),+der(?)t(6;?;2;6) } \\
\text { (?q25;?;q37q14.3;p12p25)[11]/49,idem,+der(6),del(13)(q21q33) } \\
\text { [2]/96,idemx2[4]/46,XX[3].ish } \\
\text { der(6)(wcp6+),der(?)t(6;?;2;6)(wcp6+,wcp2+,wcp6+) }\end{array}$ & $\mathrm{N}$ \\
\hline $3 b$ & & & $\begin{array}{l}\text { 48,XX,+der(6)del(6)(p11.2)del(6)(q12),+der(?)t(6;?;2;6) } \\
\text { (?q25;?;q37q14.3;p12p25)[10]/49,idem,+der(6)[5]/46,XX[3] }\end{array}$ & $\mathrm{N}$ \\
\hline 4 & $10 / \mathrm{M}$ & $\begin{array}{l}\text { Proximal humerus } \\
(1.2 \times 1.3 \times 2.2)\end{array}$ & $46, X Y[18]$ & $\mathrm{N}$ \\
\hline 5 & $21 / \mathrm{F}$ & Ilium $(5.3 \times 5.5 \times 7.0)$ & $46, \mathrm{XX}[19]$ & $\mathrm{N}$ \\
\hline 6 & $12 / \mathrm{M}$ & $\begin{array}{l}\text { Proximal tibia } \\
(2.0 \times 2.3 \times 2.3)\end{array}$ & $46, \mathrm{XY}[7]$ & $\mathrm{N}$ \\
\hline 7 & $23 / \mathrm{M}$ & Ilium N/A & $46, \mathrm{XY}[20]$ & $\mathrm{N}$ \\
\hline $8 a^{c}$ & $55 / \mathrm{F}$ & $\begin{array}{l}\text { Proximal tibia } \\
(2.5 \times 6.0 \times 6.3)\end{array}$ & $46, X X, t(6 ; 9)(q 25 ; q 22), t(7 ; 12)(q 32 ; q 13)[15]$ & $\mathrm{N}$ \\
\hline $8 b^{c}$ & & & $46, X X, t(6 ; 9)(q 25 ; q 22), t(7 ; 12)(q 32 ; q 13)[10]$ & $\mathrm{N}$ \\
\hline $9^{\mathrm{c}}$ & $37 / \mathrm{F}$ & Distal femur N/A & $46, X X, \operatorname{del}(3)(\mathrm{q} 23), \mathrm{t}(4 ; 6)(\mathrm{q} 21 ; \mathrm{q} 25)[7]$ & $\mathrm{N}$ \\
\hline $10^{\mathrm{c}}$ & $13 / \mathrm{M}$ & Ilium $(5.0 \times 7.0 \times 10.0)$ & $\begin{array}{l}\text { 46,XY,inv(6)(p25q23)t(6;6)(q23;q13)[39],tas }(15 ; 21)(\mathrm{p} 13 ; \mathrm{p} 13)[6], \\
\text { tas(3;15)(q29;p13)[5],tas(11;15)(p15;p13)[5],tas(11;15) } \\
(\mathrm{p} 15 ; \mathrm{p} 13), \mathrm{r}(15)[5][\mathrm{cp} 39]\end{array}$ & $\mathrm{ABN}$ \\
\hline 11 & $44 / \mathrm{F}$ & Ulna $(1.2 \times 1.5 \times 2.2)$ & $\begin{array}{l}\text { 46,XX,t(1;6)(p35;q25),inv(9)(p11q13)c[17]/46,sl,t(3;4) } \\
(\mathrm{p} 21 ; \mathrm{p} 16)[2] / 46, X X, \operatorname{inv}(9)(\mathrm{p} 11 \mathrm{q} 13)[1]\end{array}$ & NP \\
\hline 12 & $55 / \mathrm{M}$ & $\begin{array}{l}\text { Distal tibia } \\
(2.1 \times 2.6 \times 3.4)\end{array}$ & $46, X Y, t(6 ; 9)(q 25 ; q 22)[20]$ & NP \\
\hline 13 & $47 / \mathrm{F}$ & $\operatorname{Rib}(2.0 \times 2.8 \times 3.0)$ & $\begin{array}{l}\text { 46,XX,t(1;16)(q11;q24),t(9;16)(p23;q12.1),del(13)(q13q22)[16]/46, } \\
\text { XX,t(8;14)(q22;q13),t(11;17)(q14;q25)[2]/92sl1x2[2]/46,XX[2] }\end{array}$ & NP \\
\hline 14 & $6 / \mathrm{F}$ & $\begin{array}{l}\text { Great toe, proximal } \\
\text { phalanx }(0.8 \times 0.8 \times 1.2)\end{array}$ & $46, X X, \operatorname{der}(6) \mathrm{t}(6 ; 6)(\mathrm{q} 13 ; \mathrm{q} 27), \operatorname{der}(6) \mathrm{t}(6 ; 6) \operatorname{inv}(6)(\mathrm{p} 25 \mathrm{q} 15)[8] / 46, \mathrm{XX}[12]$ & $\mathrm{ABN}$ \\
\hline
\end{tabular}

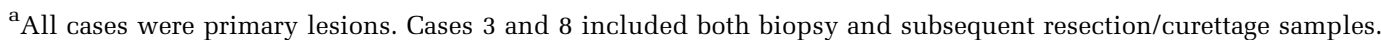

${ }^{\mathrm{b}}$ FISH conducted with the following probes: RP11-560O20, RP11-536O4, RP1-238D15, RP11-209D8, RP1-234P15.

${ }^{\mathrm{C}}$ These karyotypes have been reported previously. ${ }^{8,10}$.

N/A, not available; N, normal; ABN, abnormal; NP, not performed.
} 


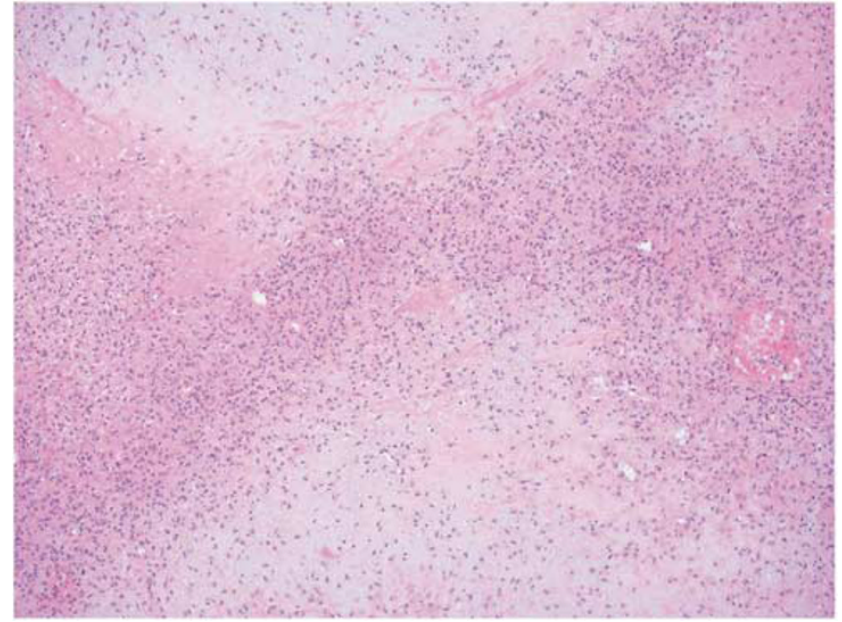

Figure 1 Chondromyxoid fibroma from case 1 exhibiting a pseudolobulated growth pattern of stellate or spindle-shaped cells in a myxoid stroma with zones of greater cellularity at the periphery of the lobules.
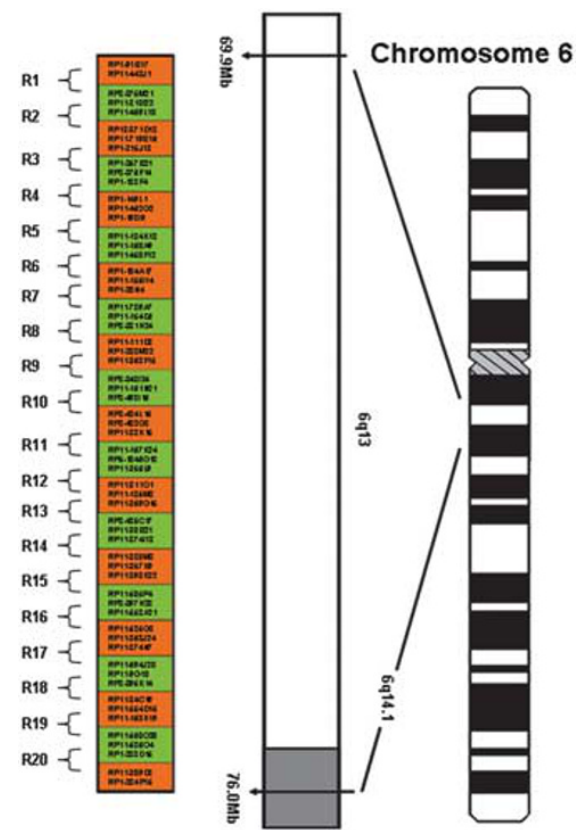

Figure 2 This schematic illustrates the different probe set combinations used to sequentially examine 20 subdivided regions spanning a $6.1 \mathrm{Mb}$ sector. The green boxes indicate probe sets labeled in Spectrum Green and the red boxes indicate probe sets labeled in Spectrum Orange.

the NCBI Map Viewer (http://www.ncbi.nlm.nih. gov/mapview) and the Ensembl Genome Browser (http://www.ensembl.org). These clones were obtained from Children's Hospital Oakland Research Institute (Oakland, CA, USA) and Research Genetics (Huntsville, AL, USA). Combinations of probe sets were fashioned to flank each defined subregion.

\section{Fluorescence In Situ Hybridization}

Fluorescence in situ hybridization (FISH) studies were performed on clonally abnormal metaphase
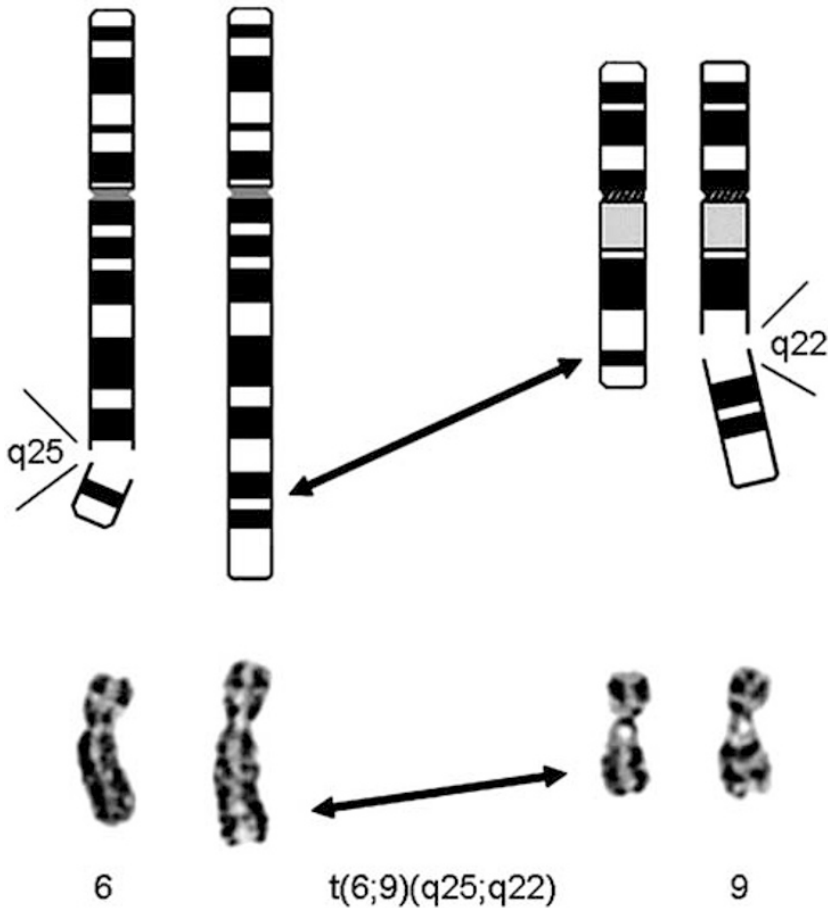

Figure 3 Schematic and partial G-banded karyotype illustrating the recurrent 6;9 translocation identified in cases 8 and 12 .

cells or cytologic touch preparations of 13 chondromyxoid fibroma samples from 11 patients. Probes were directly labeled by nick translation with either Spectrum Green or Spectrum Orange-dUTP utilizing the manufacturer's protocol (Vysis; Abbott Molecular Inc., Des Plaines, IL, USA). An amount of $1 \mu \mathrm{g}$ of DNA for each of two or three probes was combined. All nick translation reagents were then multiplied by the total micrograms of DNA used in the cocktail. Amounts of $200 \mathrm{ng}$ of each probe were hybridized and blocked approximately 15 times with a combination of human Cot-1 DNA (Invitrogen, Carlsbad, CA, USA) and human placental DNA. Spectrum aqua-labeled $\alpha$-satellite probe for the centromeric region of chromosome 6 (CEP 6 (D6Z1); Abbott Laboratories Inc., Abbott Park, IL, USA) was employed as a ploidy control.

Before hybridization, the touch preparations and in situ slides were pretreated in $2 \times$ saline sodium citrate (SSC) at $72^{\circ} \mathrm{C}$ for 2 min and in pepsin solution (20 $\mu \mathrm{l} 10 \%$ pepsin in $50 \mathrm{ml}$ of $0.1 \mathrm{~N}$ hydrochloric acid) at $37^{\circ} \mathrm{C}$ for $3 \mathrm{~min}$, washed in $1 \times$ phosphatebuffered saline (PBS) at room temperature for $5 \mathrm{~min}$, fixed in $1 \%$ formaldehyde at $4^{\circ} \mathrm{C}$ for $5 \mathrm{~min}$, and again washed in $1 \times$ PBS at room temperature for $5 \mathrm{~min}$. The slides were then dehydrated in an ethanol series $(70,85$, and $100 \%$ ) at room temperature for $2 \mathrm{~min}$ each and air dried. The cells and probes were codenatured at $75^{\circ} \mathrm{C}$ for $1 \mathrm{~min}$ and incubated at $37^{\circ} \mathrm{C}$ overnight using the HYBrite denaturation/hybridization system (Vysis). Posthybridization washing was performed in $0.4 \times \mathrm{SSC} /$ 
a

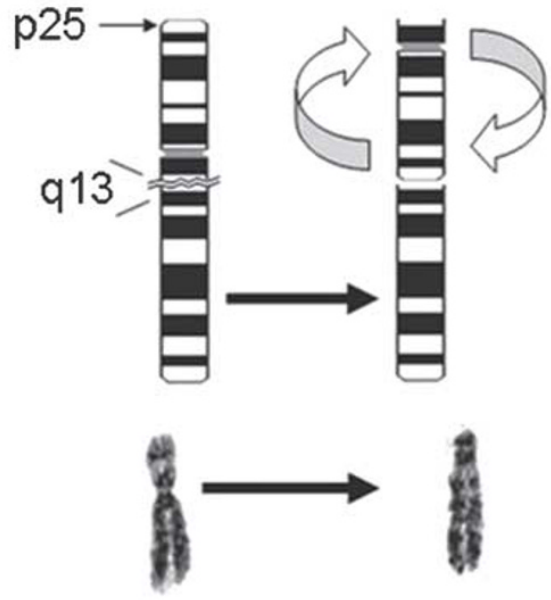

normal 6 $\operatorname{inv}(6)(\mathrm{p} 25 \mathrm{q} 13)$

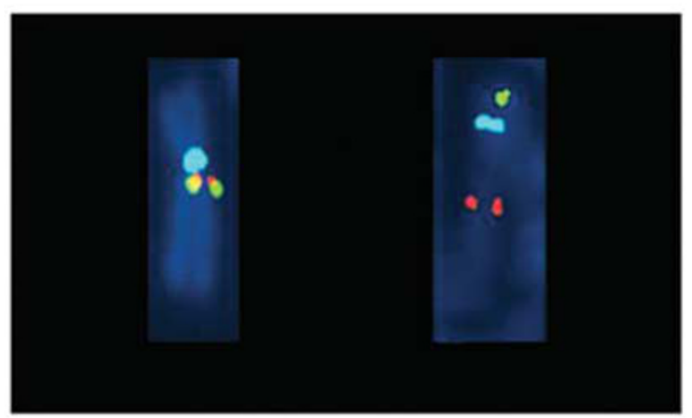

b
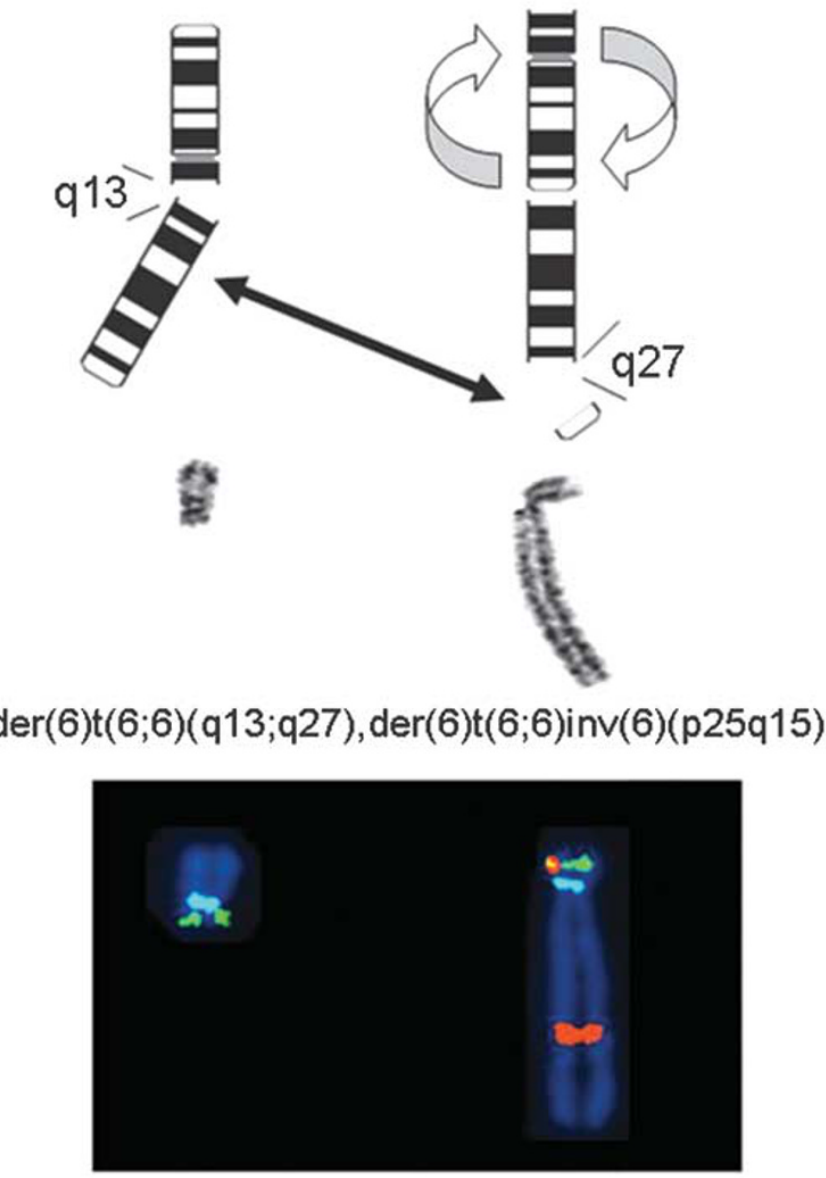

Figure 4 (a) Representative schematic, G-banded and FISH partial karyotypes of the inv(6)(p25q13) observed in case 1. With the inversion, the Spectrum Green-labeled proximal probe set (RP11-560O20, RP11-536O4, and RP1-238D15) of 'region 20' has moved to the short arm of chromosome 6. (b) Representative schematic, G-banded and FISH partial karyotypes of the complex rearrangement observed in case 20. The Spectrum Orange-labeled distal probe set (RP11-209D8 and RP1-234P15) of 'region 20' has translocated from one chromosome 6 homologue to the other chromosome 6 homologue at 6q27. The aqua signals in both (a) and (b) represent the centromeric regions of the normal and derivative chromosome 6 homologues.

$0.3 \% \mathrm{NP}-40$ at $72{ }^{\circ} \mathrm{C}$ for $2 \mathrm{~min}$, followed by $2 \times \mathrm{SSC} /$ $0.1 \% \mathrm{NP}-40$ at room temperature for $1 \mathrm{~min}$. The slides were air dried in the dark and counterstained with $4^{\prime}, 6$-diamidino-2-phenylindole (DAPI).

Each BAC or PAC clone was initially analyzed on metaphase and interphase cells of a karyotypically normal donor to confirm hybridization to the anticipated 6q13 locus with lack of cross-hybridization. Hybridization signals for each sample were assessed in 200 interphase nuclei or in 5 metaphase cells with strong, well-delineated signals by two different individuals. As additional controls, normal peripheral blood lymphocytes and cytologic touch preparations of pathologically unremarkable cartilage were simultaneously hybridized with the same probe sets. An interphase cell specimen was interpreted as abnormal for the $6 q 13$ locus if a split of flanking probe signals was detected in $>10 \%$ of the cells evaluated (more than two standard deviations above the average false positive rate). Images were acquired using the CytoVision Image Analysis System (Applied Imaging, Santa Clara, CA, USA).

\section{Results}

\section{Conventional Cytogenetic Findings}

The cytogenetic and FISH findings are summarized in Table 1. Clonal chromosomal abnormalities were detected in 11 of 16 specimens analyzed including 10 involving chromosome 6 (cases 1, 3a, 3b, 8a, 8b, $9,10,11,12$, and 13). Rearrangements of $6 q 13$ were identified in three specimens, 6p25 in five specimens, and 6q25 in five (note, an additional two specimens were suspect for a rearrangement of 6q25). Interestingly, two cases exhibited an identical $6 ; 9$ translocation $(\mathrm{t}(6 ; 9)(\mathrm{q} 25 ; \mathrm{q} 22)$; Figure 3$)$. 
COL12A1

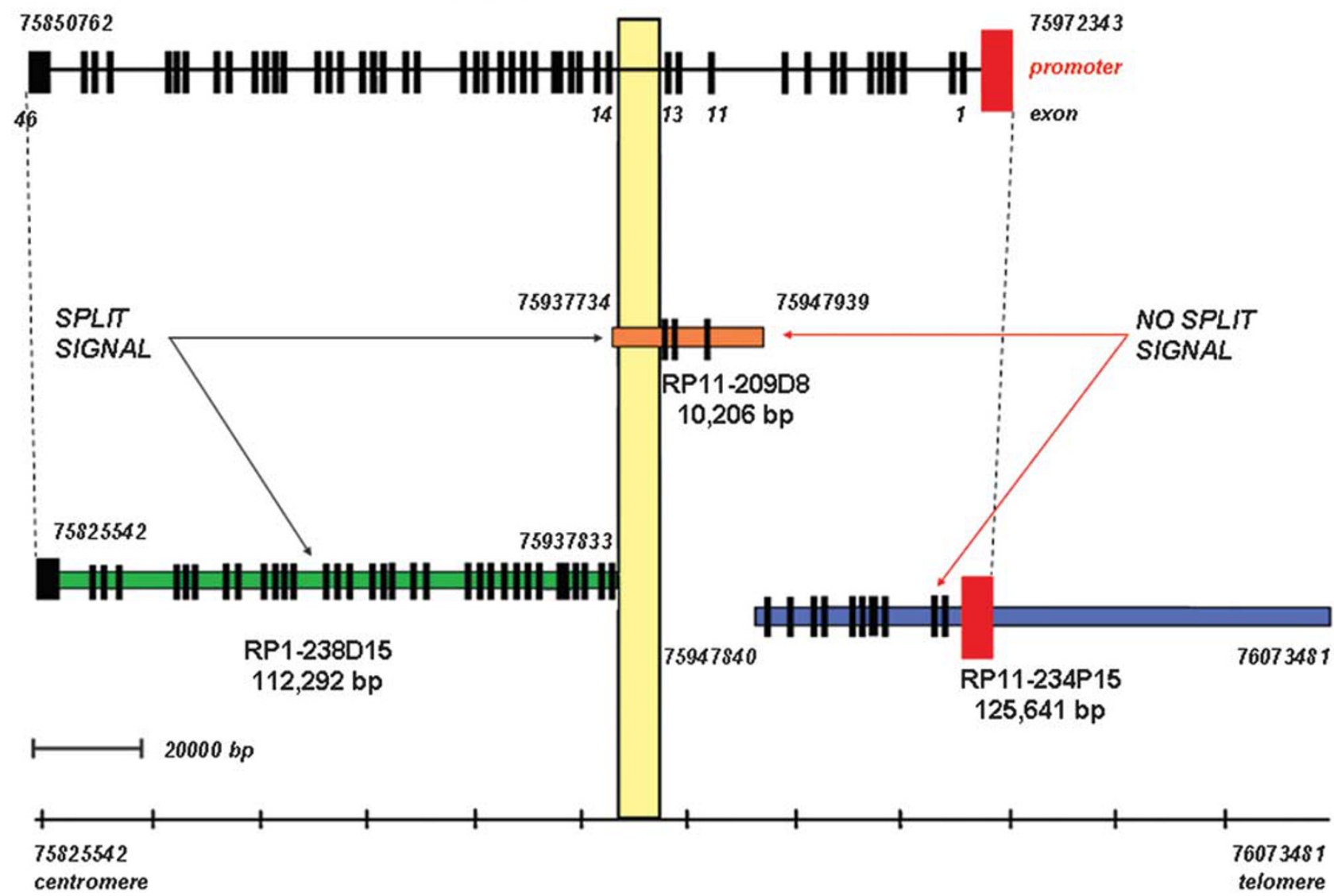

Figure 5 Schematic representation of the breakpoint mapping of the COL12A1 locus. Three BACs, RP11-234P15 (blue), RP11-209D8 (red), and RP1-238D15 (green) cover the $5^{\prime}$ region, the middle section, and the $3^{\prime}$ region, respectively, of the COL12A1 gene. Black vertical bars represent the exons and the red vertical bar the promoter region of COL12A1. Italicized numbers indicate the genomic position of the BACs and the COL12A1 gene. By FISH, the 6q13 breakpoint appears to be bound by the RP11-209D8 and RP1-238D15 BAC clones placing its location between exons 13 and 14 of COL12A1. The long yellow vertical bar depicts the position of the COL12A1 breakpoint on chromosome 6q13.

\section{Molecular Cytogenetic Findings}

Initial FISH studies were performed on cytologic touch preparations of lesional tissue from case 1 characterized by a cytogenetically confirmed inv(6)(p25q13) with 20 separate flanking probe combinations covering all 21 segments from the $6 q 13$ breakpoint, $6.1 \mathrm{Mb}$ region of interest. Only 'region 20' (Spectrum Green-dUTP-labeled proximal probes: RP11-560O20, RP11-536O4, RP1-238D15; Spectrum Orange-dUTP-labeled distal probes: RP11-209D8, RP1-234P15) showed a split of the proximal and distal probe sets indicating a disruption of this 6q13 locus. Subsequent FISH studies performed on case 1 abnormal metaphase cells with the 'region 20' probe set confirmed a disruption of signals with translocation of the proximal probe set to $6 p$ (Figure 4a).

Thirteen additional chondromyxoid fibroma specimens subjected to FISH analysis with the 'region 20' probe set showed a rearrangement of this locus in two cases (cases 10 and 14). Case 14 exhibited a translocation of the distal probe set from one chromosome 6 homologue to the other chromosome 6 homologue at 6q27 (Figure 4b). A split of one set of probe signals with loss of the probe set signal distal to 'region 20' of the 6q13 breakpoint was identified in case 10. The critical breakpoint bound by RP1-238D15 and RP11-209D8 of 'region 20' at $6 q 13$ is within the COL12A1 gene (Figure 5). The remaining 11 specimens, none of which demonstrated a 6q13 rearrangement by conventional cytogenetic analysis, were negative by FISH for a rearrangement of this locus.

\section{Discussion}

Chondromyxoid fibroma is a rare benign bone tumor composed of immature myxoid mesenchymal tissue with features of early primitive cartilaginous differentiation. ${ }^{4}$ Chondromyxoid fibroma most commonly 
Table 2 Chromosomal findings in chondromyxoid fibroma

\begin{tabular}{|c|c|c|}
\hline No. & Karyotype & Reference \\
\hline 1 & $46, \mathrm{XY}, \mathrm{t}(2 ; 13)(\mathrm{p} 14 ; \mathrm{q} 33)[3] / 47, \mathrm{idem},+5[6] / 46, \mathrm{XY}[11]$ & Bridge et $a l^{5}$ \\
\hline 2 & 46,XX,der(2)ins(5;2)(q13;p21p25),der(2)ins(5;2)(q13;p21p25),der(5)ins(5;2)(q13;p21p25)[5]/46,XX[28] & Tarkkanen et al \\
\hline 3 & $\begin{array}{l}\text { 46,XX,add(3)(p12),der(6)t(3;6)(p22;q?24)ish der(3)t(3;6)(p12;q24)(wcp3+,wcp6+), } \\
\operatorname{der}(6) \mathrm{t}(3 ; 6)(\mathrm{p} 22 ; \mathrm{q} 24)(\text { wcp6+,wcp3+,wcp6+,wcp3+)[17]/46,XX[3] }\end{array}$ & Halbert et $a l^{7}$ \\
\hline 4 & $\begin{array}{l}\text { 46,XY,inv(6)(p25q23)t(6;6)(q23;q13)[39],tas(15;21)(p13;p13)[6],tas(3;15)(q29;p13)[5], } \\
\text { tas(11;15)(p15;p13)[5],tas(11;15)(p15;p13),r(15)[5][cp39] }\end{array}$ & Sawyer et $a l^{8}$ \\
\hline 5 & 46,XY,inv(6)(p25q13)[15] & Granter et $a l^{9}$ \\
\hline 6 & 46,XY,der(6)add(6)(p23)add(6)(ql2),der(6)inv(6)(p25q13)add(6)(q26),del(12)(q22q24)[30] & Granter et $a l^{9}$ \\
\hline 7 & $46, X X$, add $(6)(q 13)$, add(7)(q21)[10] & Granter et $a l^{9}$ \\
\hline 8 & $46, X X, \operatorname{del}(6)(q 13 q 23)[4]$ & Granter et $a l^{9}$ \\
\hline 9a & $46, \mathrm{XX}, \mathrm{t}(6 ; 9)(\mathrm{q} 25 ; \mathrm{q} 22), \mathrm{t}(7 ; 12)(\mathrm{q} 32 ; \mathrm{q} 13)[15]$ & Safar et al ${ }^{10}$ \\
\hline $9 \mathrm{~b}$ & $46, \mathrm{XX}, \mathrm{t}(6 ; 9)(\mathrm{q} 25 ; \mathrm{q} 22), \mathrm{t}(7 ; 12)(\mathrm{q} 32 ; \mathrm{q} 13)[10]$ & Safar et al ${ }^{10}$ \\
\hline 10 & 46,XX,del(3)(q23),t(4;6)(q21;q25)[7] & Safar et al ${ }^{10}$ \\
\hline 11 & $46, X X$, ins $(19 ; 6)(p 13.1 ; q 13 q 25)[19] / 46, X X[1]$ & Smith et $a l^{13}$ \\
\hline 12 & 46,XX,del(6)(?q21?q23),add(7)(q21) & Tallini et $a l^{11}$ \\
\hline 13 & 46,XY,del(6)(q15),der(6)t(6;6)(q15;q27)inv(6)(p25q13)/46,XY & Tallini et $a l^{11}$ \\
\hline 14 & $46, X Y, \operatorname{inv}(6)(p 25 q 13)[15] / 46, X Y[19]$ & Sjögren et $a l^{12}$ \\
\hline 15 & $46, \mathrm{XX}, \mathrm{t}(1 ; 5)(\mathrm{p} 13 ; \mathrm{p} 13)[18] / 46, \mathrm{XX}[3]$ & Armah et $a l^{14}$ \\
\hline 16 & 45,XY,ehrb(6)(q13),der(14;21)(q10;q10)[6]/46,XY[34] & Jhala et $a l^{15}$ \\
\hline 17 & 46,XY,inv(6)(p25q13)[3]/45,X,-Y,inv(6)(p25q13),-13,+mar[2]/46,XY[14] & Current study \\
\hline $18 \mathrm{a}$ & 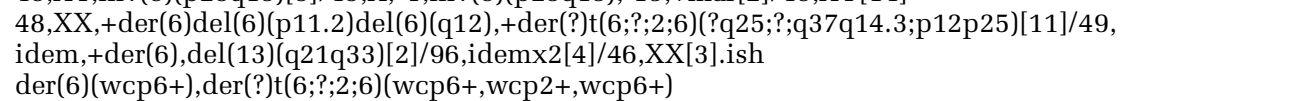 & Current study \\
\hline $18 \mathrm{~b}$ & $\begin{array}{l}\text { 48,XX,+der(6)del(6)(p11.2)del(6)(q12),+der(?)t(6;?;2;6)(?q25;?;q37q14.3;p12p25)[10]/49,idem, } \\
+\operatorname{der}(6)[5] / 46, X X[3]\end{array}$ & Current study \\
\hline 19 & 46,XX,t(1;6)(p35;q25),inv(9)(p11q13)c[17]/46,sl,t(3;4)(p21;p16)[2]46,XX,inv(9)(p11q13)[1] & Current study \\
\hline 20 & $46, X X, t(6 ; 9)(q 25 ; q 22)[20]$ & Current study \\
\hline 21 & $\begin{array}{l}\text { 46,XX,t(1;16)(q11;q24),t(9;16)(p23;q12.1),der(13)(q13;q22)[16]/46,XX,t(8;14)(q22;q13),t(11;17) } \\
(\mathrm{q} 14 ; \mathrm{q} 25)[2] / 92 \operatorname{sl} 1 \mathrm{x} 2[2] / 46, \mathrm{XX}[2]\end{array}$ & Current study \\
\hline 22 & $46, X X, \operatorname{der}(6) \mathrm{t}(6 ; 6)(\mathrm{q} 13 ; \mathrm{q} 27), \operatorname{der}(6) \mathrm{t}(6 ; 6) \operatorname{inv}(6)(\mathrm{p} 25 \mathrm{q} 15)[8] / 46, \mathrm{XX}[12]$ & Current study \\
\hline
\end{tabular}

arises as an eccentrically located lytic lesion in the metaphysis of long tubular bones. ${ }^{2}$ Histopathologically, chondromyxoid fibroma displays a pseudolobulated architecture with peripheral condensation of the neoplastic cells. ${ }^{2,4}$ A thorough coordinated evaluation of clinical, radiological, and histological features generally leads to the correct diagnosis. In some cases, however, chondromyxoid fibroma may be mistaken for chondrosarcoma because of overlapping histopathologic traits including occasional pronounced cytologic atypia. Moreover, the use of minimally invasive biopsies to diagnose bone tumors has become increasingly common, and this shift has created additional challenges. Recognition of novel diagnostic markers such as a tumor-specific chromosomal anomaly or gene rearrangement(s) could be useful in this respect.

Cytogenetic studies of chondromyxoid fibroma are few. To date, including the 11 specimens at our institution, 22 chondromyxoid fibroma specimens have reportedly shown clonal karyotypic anomalies (Table 2). ${ }^{5-15} \mathrm{~A}$ diploid or near-diploid chromosomal complement has been observed in all cases analyzed. Chromosomal abnormalities involving $6 q 13$ appear most frequent (11/22 specimens, $50 \%)$ followed by 6 p25 (9/22, 41\%) and $6 q 25$ (8/22, 36\%). An identical pericentric inversion, inv(6)(p25q13), has been detected in four chondromyxoid fibromas. ${ }^{9,11,12}$ In accordance with previous reports, this aberration was also observed in a subset of the $6 q 13$ aberrant tumors of the present series (cases 1 and 20; as a component of a more complex anomaly in the latter case). In addition, a novel translocation, $t(6 ; 9)(q 25 ; q 22)$, was identified as the sole anomaly in case 12 and as accompanied by a $7 ; 12$ translocation as the only other abnormality in case $8,{ }^{10}$ suggesting that it may represent a second diagnostic marker of chondromyxoid fibroma.

Given that the cytogenetic findings of this study and a review of the literature indicated that the $6 q 13$ locus is most commonly rearranged in chondromyxoid fibroma and likely harbors an oncogene of etiologic importance in this entity, efforts to further investigate this breakpoint were conducted. Metaphase and interphase FISH analyses revealed the key breakpoint lies within a $250 \mathrm{~kb}$ region located approximately $75.8-75.9 \mathrm{Mb}$ from the telomere of $6 \mathrm{p}$ and flanked by RP1-238D15 and RP11-209D8 at 6q13. One gene, collagen type XII alpha 1 (COL12A1), is localized to this region of overlap (http://www.ncbi.nlm.nih.gov/mapview; http://www. ensembl.org), strongly suggesting its involvement in the development of chondromyxoid fibroma. Interestingly, another collagen gene, COL15A1, resides at $9 q 22^{18}$ and it could be speculated that this gene is involved in the recurrent 6;9 translocation identified in CMF cases lacking the inv(6)(p25q13).

The collagens constitute a large group of extracellular matrix proteins that can be divided into several distinct families. The COL12A1 gene 
encodes the alpha chain of type XII collagen. Type XII collagen is a member of the fibril-associated collagens with interrupted triple helices (FACIT) family and is composed of two short collagenous triple-helical domains and three non-triple-helical domains. ${ }^{19}$ Although type XII collagen is expressed in a variety of connective tissues including articular and epiphyseal cartilage, ${ }^{20-24}$ its exact function remains poorly understood.

Recently, Storiazzi et $a{ }^{25}$ demonstrated rearrangements of the COL12A1 and COL4A5 (at Xq22) gene loci in subungual exostoses with a $t(X ; 6)(q 22 ; q 13-$ 14). However, as these two genes are oriented in opposite directions (COL12A1 is transcribed from telomere to centromere whereas COL4A5 is transcribed from centromere to telomere), the authors concluded it was unlikely that these two genes fused to create a functional chimeric gene. Rather, they suggested that COL12A1 creates a fusion transcript with a different gene on the $\mathrm{X}$ chromosome, possibly IRS4.

On a similar theme, a different collagen associated gene COL1A1 (at 17q22), is fused to $P D G F B$ (at 22q13) and USP6 (at 17p13) in dermatofibrosarcoma protuberans/giant cell fibroblastoma and aneurysmal bone cyst, respectively. ${ }^{26,27}$ For these neoplasms, the promoter region of COL1A1 is juxtaposed to the coding sequence of the fusion partner, thereby contributing to its transcriptional upregulation by promoter swapping. If the same molecular mechanism were to be applied to chondromyxoid fibroma, then it would be expected that a fusion transcript derived from the rearrangements involving 6q13 (such as the inv(6)(p25q13) identified in a subset of these tumors) would be pathogenetic. In this study, attempts to use the very limited quantity of extracted RNA available for identification of aberrant COL12A1 transcripts by RACE-PCR experiments failed (data not shown).

In conclusion, we have identified a consistent rearrangement of the COL12A1 gene locus in a subset of chondromyxoid fibromas karyotypically exhibiting 6q13 aberrations. The FISH probe sets utilized in this study represent an alternative approach for detecting 6q13 (COL12A1) rearrangements in nondividing cells of chondromyxoid fibroma as a potential adjunct in diagnostically challenging cases. In addition, we have discovered a second novel rearrangement, $t(6 ; 9)(q 25 ; q 22)$, as nonrandom in chondromyxoid fibroma. Additional studies afforded by sufficient fresh or frozen samples of this rare neoplasm are needed to further explicate how COL12A1 transcription is affected, and its potential gene partners.

\section{Acknowledgements}

This work was supported in part by Eppley Pediatric Award, Nebraska State Department of Health (LB595) and NIH (P30 CA36727). Dr Jun Nishio and Dr Taketoshi Yasuda were supported by the Gladys Pearson Fellowship in Pediatric Cancer and Genetics. We thank Ms Kimberly Christian for her expert secretarial assistance and Ms Marilu Nelson, Ms Renae Streblow, Ms Jamie Woodard, and Dr Dali Huang for their technical assistance.

\section{Disclosure/conflict of interest}

The authors declared no conflict of interest.

\section{References}

1 Jaffe HL, Lichtenstein L. Chondromyxoid fibroma of bone: distinctive benign tumor likely to be mistaken especially for chondrosarcoma. Arch Pathol 1948;45:541-551.

2 Unni KK, Inwards CY, Bridge JA, et al Chondromyxoid fibroma. In: Silverberg SG, Sobin LH (eds) AFIP Atlas of Tumor Pathology, Tumor of the Bones and Joints. ARP Press: Silver Spring, 2005. pp 67-73.

3 Wu CT, Inwards CY, O'Laughlin S, et al Chondromyxoid fibroma of bone: a clinicopathologic review of 278 cases. Hum Pathol 1998;29:438-446.

4 Ostrowski ML, Spjut HJ, Bridge JA. Chondromyxoid fibroma. In: Fletcher CDM, Unni KK, Mertens F (eds) WHO Classification of Tumours, Pathology and Genetics of Tumours of Soft Tissue and Bone. IARC Press: Lyon, France, 2002. pp 243-245.

5 Bridge JA, Sanger WG, Neff JR. Translocations involving chromosomes 2 and 13 in benign and malignant cartilaginous neoplasms. Cancer Genet Cytogenet 1989;38:83-88.

6 Tarkkanen M, Bohling $\mathrm{T}$, Helio $\mathrm{H}$, et al A recurrent chondromyxoid fibroma with chromosome aberrations ins(5;2)(q13;p21p25) and 2p deletion: a case report. Cancer Genet Cytogenet 1993;65:141-146.

7 Halbert AR, Harrison WR, Hicks MJ, et al Cytogenetic analysis of a scapular chondromyxoid fibroma. Cancer Genet Cytogenet 1998;104:52-56.

8 Sawyer JR, Swanson CM, Lukacs JL, et al Evidence of an association between 6q13-21 chromosome aberrations and locally aggressive behavior in patients with cartilage tumors. Cancer 1998;82:474-483.

9 Granter SR, Renshaw AA, Kozakewich HP, et al The pericentromeric inversion, inv(6)(p25q13), is a novel diagnostic marker in chondromyxoid fibroma. Mod Pathol 1998;11:1071-1074.

10 Safar A, Nelson M, Neff JR, et al Recurrent anomalies of $6 q 25$ in chondromyxoid fibroma. Hum Pathol 2000;31:306-311.

11 Tallini G, Dorfman H, Brys P, et al Correlation between clinicopathological features and karyotype in 100 cartilaginous and chordoid tumours: a report from the Chromosomes and Morphology (CHAMP) Collaborative Study Group. J Pathol 2002;196:194-203.

12 Sjögren H, Orndal C, Tingby O, et al Cytogenetic and spectral karyotype analyses of benign and malignant cartilage tumours. Int J Oncol 2004;24:1385-1391.

13 Smith CA, Magenis RE, Himoe E, et al Chondromyxoid fibroma of the nasal cavity with an interstitial insertion between chromosomes 6 and 19. Cancer Genet Cytogenet 2006;171:97-100.

14 Armah HB, McGough RL, Goodman MA, et al UNM. Chondromyxoid fibroma of rib with a novel chromo- 
somal translocation: a report of four additional cases at unusual sites. Diagn Pathol 2007;2:44.

15 Jhala D, Coventry S, Rao P, et al Juvenile juxtacortical chondromyxoid fibroma of bone: a case report. Hum Pathol 2008;39:960-965.

16 Althof PA, Ohmori K, Zhou M, et al Cytogenetic and molecular cytogenetic findings in 43 aneurysmal bone cysts: aberrations of $17 p$ mapped to $17 \mathrm{p} 13.2$ by fluorescence in situ hybridization. Mod Pathol 2004;17:518-525.

17 Shaffer LG, Tommerup N, (Eds) An International System for Human Cytogenetic Nomenclature. S Karger: Basel, 2005.

18 Huebner K, Cannizzaro LA, Jabs EW, et al Chromosomal assignment of a gene encoding a new collagen type (COL15A1) to 9q21-q22. Genomics 1992;14:220-224.

19 Oh SP, Taylor RW, Gerecke DR, et al The mouse $\alpha 1$ (XII) and human $\alpha 1$ (XII)-like collagen genes are localized on mouse chromosome 9 and human chromosome 6 . Genomics 1992;14:225-231.

20 Watt SL, Lunstrum GP, McDonough AM, et al Characterization of collagen types XII and XIV from fetal bovine cartilage. J Biol Chem 1992;267:20093-20099.

21 Oh SP, Griffith CM, Hay ED, et al Tissue-specific expression of type XII collagen during mouse embryonic development. Dev Dyn 1993;196:37-46.
22 Walchli C, Koch M, Chiquet M, et al Tissue-specific expression of the fibril-associated collagens XII and XIV. J Cell Sci 1994;107:669-681.

23 Dharmavaram RM, Huynh AI, Jimenez SA. Characterization of human chondrocyte and fibroblast type XII collagen cDNAs. Matrix Biol 1998;16:343-348.

24 Gregory KE, Keene DR, Tufa SF, et al Developmental distribution of collagen type XII in cartilage: association with articular cartilage and the growth plate. J Bone Miner Res 2001;16:2005-2016.

25 Storiazzi CT, Wozniak A, Panagopoulos I, et al Rearrangements of the COL12A1 and COL4A5 genes in subungual exostosis: molecular cytogenetic delineation of the tumor-specific translocation $\mathrm{t}(\mathrm{X} ; 6)(\mathrm{q} 13-$ 14;q22). Int J Cancer 2006;118:1972-1976.

26 Simon M-P, Pedeutour F, Sirvent N, et al Deregulation of the platelet-derived growth factor $\beta$-chain gene via fusion with collagen gene COL1A1 in dermatofibrosarcoma protuberans and giant cell fibroblastoma. Nat Genet 1997;15:95-98.

27 Oliveira AM, Perez-Atayde AR, Dal Cin P, et al Aneurysmal bone cyst variant translocations upregulate USP6 transcription by promoter swapping with the ZNF9, COL1A1, TRAP150, and OMD genes. Oncogene 2005;24:3419-3426. 